\title{
Epidemiology and Seasonality of Endemic Human Coronaviruses in South African and Zambian Children: A Case-Control Pneumonia Study
}

\author{
Vicky L. Baillie ${ }^{1,2, *(1)}$, David P. Moore ${ }^{1,2,3}$, Azwifarwi Mathunjwa ${ }^{1,2}$, Daniel E. Park ${ }^{4,5}$, Donald M. Thea ${ }^{6}$, \\ Geoffrey Kwenda ${ }^{7}$, Lawrence Mwananyanda ${ }^{8}$ and Shabir A. Madhi ${ }^{1,2}$ \\ 1 Medical Research Council: Vaccines and Infectious Diseases Analytics, University of the Witwatersrand, \\ Johannesburg 2050, South Africa; David.Moore@wits.ac.za (D.P.M.); azwifarwim@nicd.ac.za (A.M.); \\ Shabir.Madhi@wits.ac.za (S.A.M.) \\ 2 Department of Science and Technology/National Research Foundation: Vaccine Preventable Diseases Unit, \\ University of the Witwatersrand, Johannesburg 2050, South Africa \\ 3 Department of Paediatrics \& Child Health, Chris Hani Baragwanath Academic Hospital and University of the \\ Witwatersrand, Johannesburg 1864, South Africa \\ 4 Department of International Health, International Vaccine Access Center, Johns Hopkins Bloomberg School of \\ Public Health, Baltimore, MD 21205, USA; danpark@email.gwu.edu \\ 5 Milken Institute School of Public Health, Department of Epidemiology, George Washington University, \\ Washington, DC 20052, USA \\ check for \\ updates \\ Citation: Baillie, V.L.; Moore, D.P.; \\ Mathunjwa, A.; Park, D.E.; Thea, \\ D.M.; Kwenda, G.; Mwananyanda, L.; \\ Madhi, S.A. Epidemiology and \\ Seasonality of Endemic Human \\ 6 Department of Global Health, Boston University School of Public Health, Boston, MA 02118, USA; \\ dthea@bu.edu \\ 7 Department of Biomedical Sciences, School of Health Sciences, University of Zambia, Lusaka 50110, Zambia; \\ jaffekwenda@gmail.com \\ 8 Right to Care-Zambia, Department of Global Health, Boston University School of Public Health, \\ Boston, MA 02118, USA; Lawrence.Mwananyanda@righttocare-zambia.org \\ * Correspondence: vicky.baillie@wits-vida.org; Tel.: +27-11-983-4283
} Coronaviruses in South African and Zambian Children: A Case-Control Pneumonia Study. Viruses 2021, 13, 1513. https://doi.org/10.3390/ v13081513

Academic Editors: Luis

Martinez-Sobrido and Fernando Almazan Toral

Received: 18 June 2021

Accepted: 29 July 2021

Published: 31 July 2021

Publisher's Note: MDPI stays neutral with regard to jurisdictional claims in published maps and institutional affiliations.

Copyright: (c) 2021 by the authors. Licensee MDPI, Basel, Switzerland. This article is an open access article distributed under the terms and conditions of the Creative Commons Attribution (CC BY) license (https:// creativecommons.org/licenses/by/ $4.0 /)$.

\begin{abstract}
Endemic human coronaviruses $(\mathrm{HCoV})$ are capable of causing a range of diseases from the common cold to pneumonia. We evaluated the epidemiology and seasonality of endemic HCoVs in children hospitalized with clinical pneumonia and among community controls living in countries with a high HIV burden, namely South Africa and Zambia, between August 2011 to October 2013. Nasopharyngeal/oropharyngeal swabs were collected from all cases and controls and tested for endemic $\mathrm{HCoV}$ species and 12 other respiratory viruses using a multiplex real-time PCR assay. We found that the likelihood of detecting endemic $\mathrm{HCoV}$ species was higher among asymptomatic controls than cases (11\% vs. $7.2 \%$; 95\% CI: 1.2-2.0). This was however only observed among children $>6$ months and was mainly driven by the Betacoronavirus endemic species (HCoV-OC43 and -HKU1). Endemic HCoV species were detected through the year; however, in Zambia, the endemic Betacoronavirus species tended to peak during the winter months (May-August). There was no association between HIV status and endemic HCoV detection.
\end{abstract}

Keywords: coronavirus; epidemiology; childhood; pneumonia

\section{Introduction}

Coronaviruses (CoVs) from the family Coronaviridae (Order Nidovirales) are enveloped, single-stranded, zoonotic RNA viruses [1]. There are four genera of CoVs, two of whichAlphacoronaviruses and Betacoronaviruses-are capable of infecting humans causing a variety of symptoms, ranging from gastrointestinal to cardiac and respiratory disease. Further, the respiratory disease can range from a common cold to more severe infections, including bronchitis and pneumonia [2,3]. Four endemic human coronaviruses (HCoVs) are commonly detected in humans, namely HCoV-229E, -HKU1, -NL63 and -OC43 [3]. More recently, novel severe acute respiratory syndrome CoV (SARS-CoV) emerged in 2002, Middle 
East respiratory syndrome CoV (MERS-CoV) in 2012 and the 2019 novel CoV (SARS-CoV-2) is currently causing a global pandemic with symptoms ranging from mild respiratory and gastrointestinal disease to severe pneumonia and death. HCoV-OC43, -HKU1, SARS-CoV, SARS-CoV-2 and MERS-CoV are all part of the Betacoronavirus genera and HCoV-229E and NL63 are part of the Alphacoronavirus genera [3]. Endemic HCoVs are most commonly detected as co-infections with other respiratory viruses [2-5] or in immunocompromised children with underlying chronic disease [3,4]. However, limited information is available on the interactions between HCoVs and human immunodeficiency virus type-1 (HIV), and severity of disease.

In this study, we analyzed the prevalence of endemic $\mathrm{HCoV}$ species among children $<5$ years of age hospitalized with pneumonia, together with age-matched community controls, living in two African countries with high HIV prevalence, namely South Africa and Zambia.

\section{Materials and Methods}

\subsection{Case and Control Definitions}

This study was undertaken in two sites which had a high HIV prevalence, namely Soweto, South Africa (920 cases and 964 controls) and Lusaka, Zambia (617 cases and 686 controls), from August 2011 through January 2014. Details on enrolment of cases and controls, sample testing and clinical evaluation in the Pneumonia Etiology Research for Child Health (PERCH) study have been published [6,7]. Briefly, cases were children hospitalized with World Health Organization (WHO) criteria of clinically defined severe or very-severe pneumonia, and controls were children actively recruited from the same community in which cases resided. Controls were age-frequency, HIV-status and seasonally matched to cases. The controls were analytically stratified into those with respiratory tract infection (RTI), including if they had a cough, runny nose, ear discharge, wheezing or difficulty breathing together with either a fever (temperature $\geq 38^{\circ} \mathrm{C}$ in the past $48 \mathrm{~h}$ ) or a sore throat but absence of signs of severe pneumonia, and those without RTI. This was a cross-sectional study, so cases and controls were sampled, and detailed demographic and clinical data obtained at the time of enrolment into the study. This clinical assessment was how RTI $(n=165)$ and asymptomatic controls $(n=1485)$ were identified.

\subsection{Specimen Collection and Laboratory Testing}

Flocked nasopharyngeal (NP) swab (Flexible minitip, Copan ${ }^{\circledR}$ ) and rayon oropharyngeal $(\mathrm{OP})$ swab specimens were collected from all cases and controls on enrolment into the study. The swabs were placed together in a vial containing $3 \mathrm{~mL}$ of Universal Transport Medium $\left(\mathrm{Copan}^{\circledR}\right)$. The NP/OP specimens were maintained at $4-8{ }^{\circ} \mathrm{C}$ for a maximum of $24 \mathrm{~h}$ and then archived at $-70{ }^{\circ} \mathrm{C}$ until tested. Total nucleic acids were extracted from the NP/OP swabs using the NucleiSens EasyMag extraction system as per manufactures instructions (BioMerieux, Marcy l'Etoile, France) and were tested by multiplex real-time PCR (FTD Resp 33, Fast-track Diagnostics, Sliema, Malta) [8]. The FTD Resp 33 panels detected for 19 viruses (HRV (A, B and C not differentiated), Influenza virus (A, B and C separately), PIV (1, 2, 3 and 4 separately), Coronavirus (HKU1, OC43, NL63, 229E separately), Bocavirus, Human Metapneumoviruses (A and B not differentiated), RSV (A and B not differentiated), Cytomegalovirus (CMV), Adenovirus, Enterovirus and Parechovirus), 11 bacteria (Streptococcus pneumoniae, Staphylococcus aureus, Haemophilus influenzae and Haemophilus influenzae type B, Moraxella cattarahalis, Legionella spp., Salmonella spp., Chlamydia pneumoniae, Mycoplasma pneumoniae, Klebsiella pneumoniae and Bordetella pertussis) and the fungus Pneumocystis jiroveci. All samples were tested in the same country they were collected using standard operating procedures across all sites and standard curves were used to calculate pathogen load from PCR cycle threshold values [8].

Other tests included blood culture on cases, which were processed using the BacT/Alert microbial system (Organon Teknika, Durham, NC, USA) or the BD BACTEC FX200 blood culture system (BD Biosciences, Franklin Lakes, NJ, USA). Standard diagnostics were also 
conducted on all case blood samples to determine white blood cell counts (cases only) and C-reactive protein (CRP) levels (in cases and a subset of controls). Microbiologically confirmed pneumococcal pneumonia (MCPP) was defined as Streptococcus pneumoniae cultured from a normally sterile fluid. In addition, in the PERCH study a strong association was observed between high pneumococcal densities in the NP ( $>6.9 \log _{10}$ copies $\left./ \mathrm{mL}\right)$ [9] or whole blood ( $>2.2 \log _{10}$ copies $/ \mathrm{mL}$ ) samples [10] and the presence of MCPP. Cases with high density pneumococcal (HDP) thresholds and/or MCPP were used to analyze the relationship between $\mathrm{HCoVs}$ and pneumococcal pneumonia.

\subsection{Statistical Analysis}

PCR pathogen loads were $\log _{10}$ transformed. Chi-squared and Wilcoxon tests were used to analyze the demographic characteristics of cases and controls. Binary, multinomial logistic regression and odds ratio analysis were used to model the prevalence of $\mathrm{HCoV}$, Betacoronavirus and Alphacoronavirus within the study population. Binary and multinomial logistic regression analyses were used to model the prevalence of $\mathrm{HCoV}$ within the study population. Age categories and site of enrolment together with variables with an association at $p<0.2$ in the univariate analysis were included in the multivariable models. All statistical analysis was performed using STATA Version 12.1 (College Station, TX, USA) and a twosided $p$-value $<0.05$ was considered statistically significant.

\section{Results}

Overall, community controls were more likely to have $\mathrm{HCoV}$ detected in their NP/OP samples compared to cases (10.5\% vs. $7.2 \%$; $95 \%$ CI: 1.17-1.96); however, this association was only evident in the asymptomatic controls (11\% vs. $7.2 \%$; $95 \%$ CI: $1.2-2.0)$ (Table 1); regardless of site of enrolment (Table S1 in Supplementary Material). Further, this association was seen in HIV-uninfected (HIV-) participants ( $10 \%$ vs. $7 \%$ for controls vs. cases) as well as in children living with HIV (HIV+; $10 \%$ vs. $7 \%$ for controls vs. cases). Interestingly, the prevalence of $\mathrm{HCoV}$ detection was similar in the cases and the RTI controls. However, the HIV+ and RTI analysis lacked statistical power due to the small number of $\mathrm{HCoV}$ positive participants.

The association with asymptomatic controls was driven by the Betacoronavirus endemic species (HKU1-HCoV and OC43-HCoV) and in particular HCoV-HKU1 (Table S2 in Supplementary Material), whereas the Alphacoronavirus endemic species (229E-HCoV and NL63-HCoV) were not associated with case or control status. Similar associations were only observed when the asymptomatic controls were compared to the cases (Table 1).

By age group, the association of $\mathrm{HCoV}$ detection being associated with asymptomatic controls was only evident in children $>6$ months of age. There were no significant differences in the prevalence of HCoVs detected among HIV+ and HIV - cases and controls. Once again, the association of $\mathrm{HCoV}$ with controls $>6$ months of age was driven by the Betacoronavirus endemic species (Table S3 in Supplementary Material).

$\mathrm{HCoV}$ was detected as the only respiratory virus present in the nasopharynx/ oropharynx of significantly more of the asymptomatic controls than the cases. However, $\mathrm{HCoV}+$ cases were more likely to have co-infections with RSV, HBoV and AdV compared to the $\mathrm{HCoV}+$ asymptomatic controls. Additionally, compared to the $\mathrm{HCoV}+$ asymptomatic controls the $\mathrm{HCoV}+$ cases were more likely to have high density of pneumococcus $\left(>6.9 \log _{10}\right.$ copies $/ \mathrm{mL}$ ) on NP/OP swabs. There were no differences in the prevalence of bacterial co-infections in the NP/OP of the $\mathrm{HCoV}+$ cases and asymptomatic controls (Table 2). Similar trends were seen among the HIV - and HIV+ cases and controls, but the HIV+ analysis lacked statistical power to detect differences (Tables S4 and S5 in Supplementary Material). 
Table 1. Number of study subjects enrolled and tested for HCoV-percent positive by age and HIV-1 infection status.

\begin{tabular}{|c|c|c|c|c|c|c|}
\hline Age Group & & & Total N (\%) & HIV+ N (\%) & HIV - N (\%) & \\
\hline \multirow[t]{24}{*}{ Overall } & Enrolled & Cases & 1537 & 218 & 1316 & \\
\hline & & $\begin{array}{l}\text { Asymptomatic } \\
\text { controls }\end{array}$ & 1485 & 170 & 1306 & \\
\hline & & RTI Controls & 165 & 51 & 113 & \\
\hline & $\mathrm{HCoV}^{\mathrm{g}}$ & Cases & $104(7)$ & $16(7)$ & $88(7)$ & \\
\hline & & Controls & $164(11)$ & $21(10)$ & $141(10)$ & $p=0.569^{\mathrm{f}}$ \\
\hline & & & $p=0.002^{c}$ & $p=0.385^{c}$ & $p=0.002^{c}$ & \\
\hline & & $\begin{array}{c}\text { Asymptomatic } \\
\text { control }^{\text {a }}\end{array}$ & 155 (11) & $18(11)$ & $135(11)$ & $p=0.357^{\mathrm{f}}$ \\
\hline & & & $p=0.001^{\mathrm{d}}$ & $p=0.320^{\mathrm{d}}$ & $p=0.001^{\mathrm{d}}$ & \\
\hline & & RTI control $^{b}$ & $9(6)$ & $3(7)$ & $6(6)$ & $p=0.167^{\mathrm{f}}$ \\
\hline & & & $p=0.698^{\mathrm{e}}$ & $p=0.817^{\mathrm{e}}$ & $p=0.738^{\mathrm{e}}$ & \\
\hline & AlphaCoV ${ }^{\mathrm{h}}$ & Cases & $44(3)$ & $6(3)$ & $38(3)$ & \\
\hline & & Controls & $59(4)$ & $4(2)$ & $54(4)$ & $p=0.336^{\mathrm{f}}$ \\
\hline & & & $p=0.232^{c}$ & $p=0.362^{c}$ & $p=0.140^{c}$ & \\
\hline & & $\begin{array}{l}\text { Asymptomatic } \\
\text { control }^{\mathrm{a}}\end{array}$ & $55(4)$ & $1(2)$ & $51(4)$ & $p=0.258^{\mathrm{f}}$ \\
\hline & & & $p=0.194^{\mathrm{d}}$ & $p=0.749^{d}$ & $p=0.150^{\mathrm{d}}$ & \\
\hline & & RTI control $^{b}$ & $4(2)$ & $3(2)$ & $3(3)$ & $p=0.538^{\mathrm{f}}$ \\
\hline & & & $p=0.746^{\mathrm{e}}$ & $p=0.521^{\mathrm{e}}$ & $p=0.887^{\mathrm{e}}$ & \\
\hline & BetaCov ${ }^{i}$ & Cases & $63(4)$ & $11(5)$ & $52(4)$ & \\
\hline & & Controls & $111(7)$ & $17(8)$ & $92(6)$ & $p=0.922^{\mathrm{f}}$ \\
\hline & & & $p=0.002^{c}$ & $p=0.244^{c}$ & $p=0.040^{c}$ & \\
\hline & & $\begin{array}{c}\text { Asymptomatic } \\
\text { control }^{\text {a }}\end{array}$ & $106(7)$ & $2(4)$ & $89(7)$ & $p=0.217^{\mathrm{f}}$ \\
\hline & & & $p=0.002^{\mathrm{d}}$ & $p=0.736^{\mathrm{d}}$ & $p=0.001^{\mathrm{d}}$ & \\
\hline & & RTI control $^{b}$ & $5(3)$ & $15(9)$ & $3(3)$ & $p=0.477^{\mathrm{f}}$ \\
\hline & & & $p=0.505^{\mathrm{e}}$ & $p=0.140^{\mathrm{e}}$ & $p=0.492^{\mathrm{e}}$ & \\
\hline
\end{tabular}

Abbreviations: n: number; HCoVs: Human coronaviruses; HIV: Human immunodeficiency virus; RTI: Respiratory tract infections. a-Asymptomatic controls were controls presenting with no obvious signs or symptoms of respiratory tract infections at the time of sample collection. $\mathrm{b}$-Controls were considered to have RTI if they had (1) cough or runny nose, or (2) one of the following signs, ear discharge, wheeze, or difficulty breathing, in the presence of sore throat or fever (temperature $\geq 38.0^{\circ} \mathrm{C}$ or reported fever in the past $48 \mathrm{~h}$ ). $\mathrm{c}-p$-values adjusted for age in months and site of enrolment where applicable, comparing the $\mathrm{HCoV}$ prevalence among cases and controls. $\mathrm{d}-p$-values adjusted for age in months and site of enrolment where applicable, comparing the $\mathrm{HCoV}$ prevalence among cases and asymptomatic controls. $\mathrm{e}-p$-values adjusted for age in months and site of enrolment where applicable, comparing the $\mathrm{HCoV}$ prevalence among cases and RTI controls. $\mathrm{f}-p$-value adjusting for age in months and site of enrolment where applicable, comparing the HCoV prevalence HIV+ and HIV - cases and controls. g-any HCoV species (OC43 and/or NL43 and/or E229 and/or HKU1). h-Alphacoronavirus, HKU1-HCoV and OC43-HCoV. i-Betacoronavirus, 229E-HCoV and NL63-HCoV.

In Zambia, $\mathrm{HCoV}$ infections in both cases and asymptomatic controls occurred mainly during the winter months-July to September. However, in South Africa the seasonal distribution was less well defined with cases and controls having different peaks in prevalence's (Figure 1). Among the Alphacoronavirus endemic species, HCoV-NL63 and -229E, the peaks tended to occur later in the year in the warmer months (November-January); whereas the Betacoronavirus endemic species, $\mathrm{HCoV}-\mathrm{OC} 43$ and -HKU1, tended to peak in the colder months (May-August; Figure 2). 
Table 2. HCoV among cases $(n=104)$ and asymptomatic controls $(n=164)$ at South African and Zambian sites.

\begin{tabular}{|c|c|c|c|c|}
\hline Characteristics & Cases N (\%) & $\begin{array}{l}\text { Asymptomatic } \\
\text { Controls N (\%) }\end{array}$ & aOR $(95 \% C I)$ & $p$-Value ${ }^{\text {a }}$ \\
\hline \multicolumn{5}{|l|}{ HCoV epidemiology } \\
\hline $\begin{array}{c}\text { HCoV detected as } \\
\text { single viral infections }\end{array}$ & $38(36)$ & $89(57)$ & $2.64(1.55-4.53)$ & $<0.001$ \\
\hline HCoV-E229 & $8(8)$ & $6(4)$ & $0.49(0.16-1.49)$ & 0.206 \\
\hline HCoV-NL63 & $36(35)$ & $49(32)$ & $0.91(0.53-1.56)$ & 0.730 \\
\hline HCoV-OC43 & $42(40)$ & $66(43)$ & 1.07 (0.63-1.81) & 0.802 \\
\hline HCoV-HKU1 & $21(20)$ & $40(26)$ & $1.32(0.72-2.44)$ & 0.367 \\
\hline HCoV load, mean (SD) & $5.29(0.77)$ & $5.29(0.68)$ & - & 0.973 \\
\hline $\begin{array}{l}\text { Load in } \mathrm{HCoV} \text { single } \\
\text { infections }\end{array}$ & $5.43(0.27)$ & $5.33(0.17)$ & - & 0.77 \\
\hline $\begin{array}{l}\text { Load in HCoV mixed } \\
\text { infections }\end{array}$ & $5.18(0.22)$ & $5.23(0.20)$ & - & 0.87 \\
\hline \multicolumn{5}{|l|}{$\begin{array}{l}\text { Mixed viral infections } \\
\text { in the NP/OP }\end{array}$} \\
\hline Two HCoV species ${ }^{c}$ & $3(3)$ & $2(1)$ & $0.59(0.22-2.45)$ & 0.39 \\
\hline RSV & $24(23)$ & $2(1)$ & $0.05(0.01-0.21)$ & $<0.001$ \\
\hline $\operatorname{InFV}(\mathrm{A}, \mathrm{B}$ and $\mathrm{C})$ & $4(4)$ & $2(1)$ & $0.22(0.03-1.40)$ & 0.108 \\
\hline $\mathrm{AdV}$ & $14(13)$ & $10(6)$ & $0.34(0.14-0.82)$ & 0.017 \\
\hline $\mathrm{HBoV}$ & $19(18)$ & $17(11)$ & $0.47(0.22-0.98)$ & 0.045 \\
\hline RV & $20(19)$ & $28(18)$ & $0.92(0.48-1.76)$ & 0.806 \\
\hline PIV (1-4) & $2(2)$ & $4(3)$ & $1.26(0.21-7.40)$ & 0.797 \\
\hline \multicolumn{5}{|l|}{$\begin{array}{c}\text { Bacterial co-infections } \\
\text { in the NP/OP }\end{array}$} \\
\hline H. influenzae type b & $5(5)$ & $2(1)$ & $0.24(0.05-1.33)$ & 0.104 \\
\hline B. pertussis & $2(2)$ & $1(1)$ & $0.41(0.04-4.72)$ & 0.473 \\
\hline S. aureus & $21(20)$ & $23(15)$ & $0.86(0.43-1.71)$ & 0.658 \\
\hline H. influenzae & $52(50)$ & $73(47)$ & $0.79(0.47-1.33)$ & 0.377 \\
\hline S. pneumoniae & $74(71)$ & $114(74)$ & 1.09 (0.61-1.95) & 0.773 \\
\hline M. pneumoniae & $1(1)$ & $3(2)$ & $1.27(0.12-13.5)$ & 0.840 \\
\hline M. catarrhalis & $71(68)$ & $116(75)$ & $1.39(0.79-2.47)$ & 0.257 \\
\hline C. pneumoniae & 0 & $5(3)$ & - & 0.082 \\
\hline $\begin{array}{l}\mathrm{HCoV} \text { and } S \text {. } \\
\text { pneumoniae } \\
\text { co-infections }\end{array}$ & & & & \\
\hline S. pneu load, mean (SD) & $5.42(0.16)$ & $5.77(1.37)$ & - & 0.067 \\
\hline HDP in nasopharynx ${ }^{f}$ & $15(14)$ & $11(7)$ & $2.46(1.06-5.67)$ & 0.035 \\
\hline S. pneu detected in WB & $5(5)$ & $11(7)$ & $1.38(0.45-4.25)$ & 0.570 \\
\hline
\end{tabular}

Abbreviations: HCoV: human coronavirus; aOR: adjusted odds ratio; CI: confidence interval; WB: whole blood; RV: rhinovirus; RSV: respiratory syncytial virus, HMPV: human metapneumovirus; PIV: parainfluenza types 1-4; HBoV: human bocavirus; AdV: adenovirus; InFV: influenza virus (A, B and C); S. aureus: Staphylococcus aureus; S. pneu: Streptococcus pneumoniae; H. influenzae: Haemophilus influenzae, H. influenzae type, M. catarrhalis: Moraxella catarrahalis. B. pertussis: Bordetella pertussis; M. pneumoniae: Mycoplasma pneumoniae; C. pneumoniae: Chlamydia pneumoniae; HDP: High density pneumococcus. a- $p$-values and aOR from regression models adjusted for age in months, site of enrolment, and confounding covariates where applicable. b-Human Coronavirus including either OC43, NL63, $229 \mathrm{E}$ or HKU1. c-Human Coronavirus including OC43 and/or NL63 and/or 229E and/or HKU1. d-HCoV viral load in the nasopharynx expressed as $\log _{10}$ copies $/ \mathrm{mL}$. e-S. pneumoniae bacterial load in the nasopharynx expressed as $\log _{10}$ copies $/ \mathrm{mL}$. $\mathrm{f}-\mathrm{HDP}$ defined as S. pneumoniae density in nasopharynx $>6.9 \log _{10}$ copies $/ \mathrm{mL}$. 


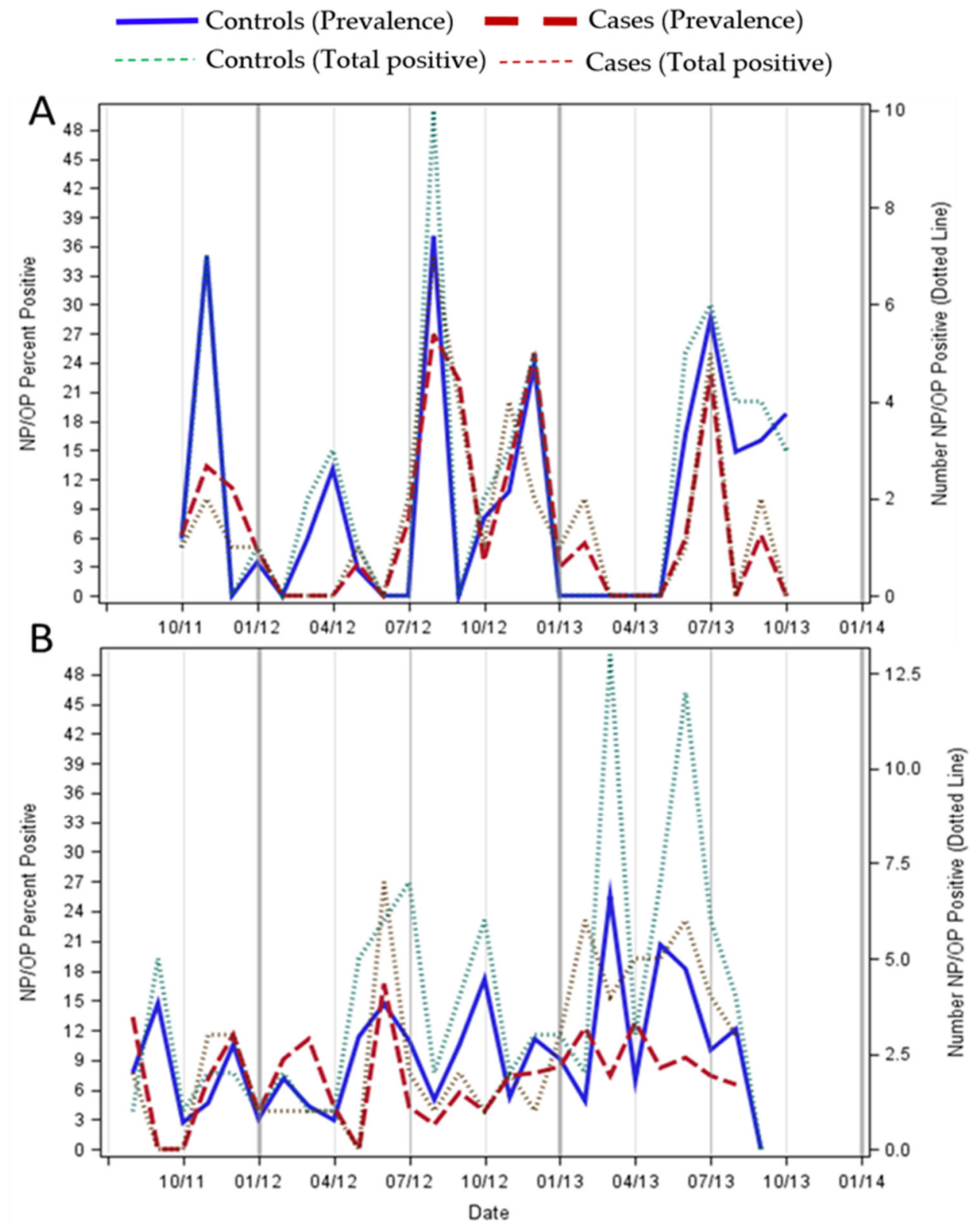

Figure 1. The seasonal distribution of $\mathrm{HCoV}$ over a period of two years in children hospitalized with pneumonia and asymptomatic controls in Zambia (Panel (A)) and South Africa (Panel (B)). Prevalence is the $\%$ of samples that tested positive for $\mathrm{HCoV}$ for each month for cases (dashed red line) and controls (solid blue line), with the actual number of $\mathrm{HCoV}$ positives for each month on the $\mathrm{z}$ axis for cases (dotted green line) and controls (dotted red line). 

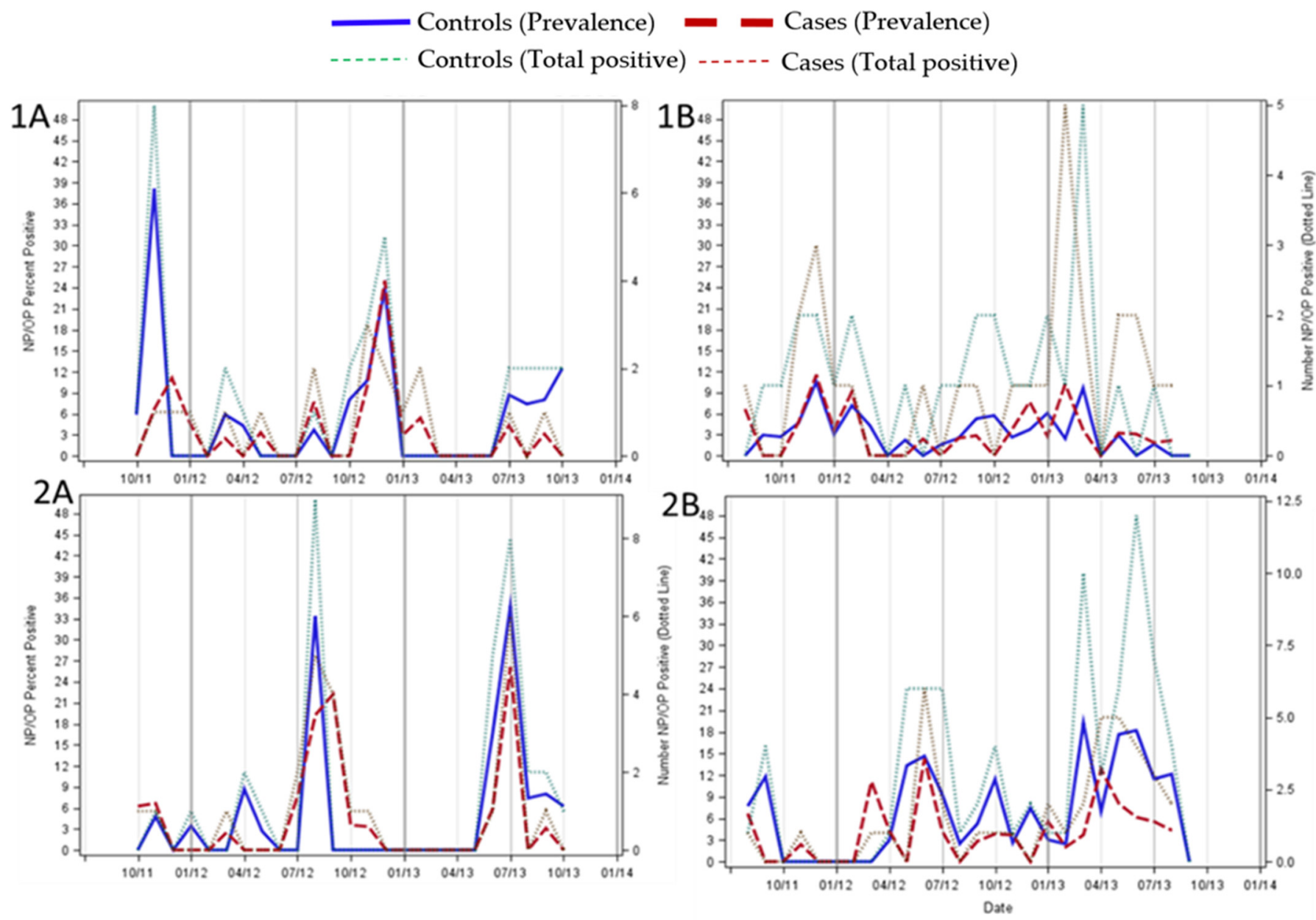

Figure 2. The seasonal distribution of Alphacoronavirus endemic species (Panel (1A) and (1B)) and Betacoronavirus endemic species (Panel (2A) and (2B)) over a period of two years in children hospitalized with pneumonia and asymptomatic controls in Zambia (Panel (1A) and (2A)) and South Africa (Panel (1B) and (2B)). Prevalence is the \% of samples that tested positive for $\mathrm{HCoV}$ for each month for cases (dashed red line) and controls (solid blue line), with the actual number of $\mathrm{HCoV}$ positives for each month on the $\mathrm{z}$ axis for cases (dotted green line) and controls (dotted red line).

Among children with pneumonia, $\mathrm{HCoV}$ was not associated with very severe pneumonia; there was however a trend for the Betacoronavirus endemic species to be more associated with very severe pneumonia and longer hospital stays ( $>5$ days) compared to $\mathrm{HCoV}$ - cases. Additionally, the Betacoronavirus endemic species were more likely to have medically significant CRP levels $(>40 \mathrm{mg} / \mathrm{mL}$ ), high density of pneumococcus $(>6.9$ $\log _{10}$ copies $/ \mathrm{mL}$ ) on NP/OP swabs and the $\mathrm{HCoV}+$ cases were more likely to have blood cultures positive for medically significant bacteria compared to $\mathrm{HCoV}$ - cases (Table 3 ). This association with blood culture positivity was mainly driven by cases were $\mathrm{HCoV}$ was the only respiratory virus detected in the nasopharynx whereas the cases where $\mathrm{HCoV}$ was detected together with other common respiratory viruses were more likely to be hypoxic (Table S6 in Supplementary Material). 
Table 3. Demographic, clinical characteristics and markers of bacterial and respiratory viral co-infections among severe and very-severe pneumonia cases identified with Human coronavirus infection.

\begin{tabular}{|c|c|c|c|c|c|c|c|}
\hline Characteristics & $\begin{array}{c}\mathrm{HCoV}^{\mathrm{a}}+ \\
(n=104) \\
\mathrm{N}(\%)\end{array}$ & $\begin{array}{c}\text { AlphaCoV b } \\
(n=44) \\
\mathrm{N}(\%)\end{array}$ & $\begin{array}{c}\text { BetaCoV c } \\
(n=63) \\
\mathrm{N}(\%)\end{array}$ & $\begin{array}{c}\text { HCoV- } \\
(n=1338) \\
\mathrm{N}(\%)\end{array}$ & $p$-Value ${ }^{\mathrm{d}}$ & $p$-Value ${ }^{\mathrm{e}}$ & $p$-Value ${ }^{\mathrm{f}}$ \\
\hline \multicolumn{8}{|l|}{ Demographics and health } \\
\hline Age (months), mean (SD) & $7.9(8.52)$ & $9.07(9.55)$ & $7.51(8.05)$ & $8.9(10.01)$ & 0.337 & 0.917 & 0.276 \\
\hline Male & $64(62)$ & $27(61)$ & $39(62)$ & $703(52)$ & 0.07 & 0.241 & 0.136 \\
\hline HIV & $16(15)$ & $6(14)$ & $11(17)$ & $188(14)$ & 0.654 & 0.921 & 0.409 \\
\hline \multicolumn{8}{|l|}{ Clinical features } \\
\hline Very severe pneumonia & $37(35)$ & $10(23)$ & $27(43)$ & $428(32)$ & 0.463 & 0.204 & 0.08 \\
\hline Chest X-ray abnormal $\mathrm{g}$ & $57(58)$ & $22(53)$ & $37(63)$ & $693(54)$ & 0.583 & 0.712 & 0.26 \\
\hline Hypoxic $^{\mathrm{h}}$ & $69(67)$ & $27(63)$ & $44(70)$ & $829(62)$ & 0.274 & 0.807 & 0.175 \\
\hline Tachycardia $^{\mathrm{i}}$ & $59(57)$ & $29(67)$ & $33(53)$ & $737(55)$ & 0.696 & 0.111 & 0.606 \\
\hline Tachypnea j & $83(82)$ & $38(86)$ & $48(79)$ & $1081(82)$ & 0.999 & 0.439 & 0.607 \\
\hline Wheezing & $24(23)$ & $11(26)$ & $14(22)$ & $321(24)$ & 0.948 & 0.785 & 0.855 \\
\hline Convulsions & $2(2)$ & $1(2)$ & $1(2)$ & $38(3)$ & 0.613 & 0.793 & 0.582 \\
\hline Diarrhea & $16(15)$ & $6(14)$ & $10(16)$ & $238(18)$ & 0.485 & 0.473 & 0.636 \\
\hline Hospital stay $>5$ days & $59(57)$ & $20(45)$ & $39(62)$ & $665(50)$ & 0.174 & 0.619 & 0.06 \\
\hline Died in Hospital & $9(9)$ & $4(9)$ & $5(8)$ & $127(9)$ & 0.755 & 0.912 & 0.643 \\
\hline \multicolumn{8}{|l|}{ Bacterial co-infection markers } \\
\hline Fever $^{k}$ & $74(71)$ & $30(68)$ & $46(73)$ & $963(72)$ & 0.947 & 0.573 & 0.782 \\
\hline Leukocytosis ${ }^{1}$ & $593(45)$ & $51(50)$ & $19(44)$ & $34(54)$ & 0.302 & 0.925 & 0.122 \\
\hline $\mathrm{CRP}>40 \mathrm{mg} / \mathrm{L}^{\mathrm{m}}$ & $35(34)$ & $12(27)$ & $25(40)$ & $381(28)$ & 0.186 & 0.848 & 0.034 \\
\hline Blood culture positive ${ }^{n}$ & $8(8)$ & $3(7)$ & $5(8)$ & $47(4)$ & 0.039 & 0.266 & 0.084 \\
\hline $\mathrm{MCPP}^{\circ}$ & $1(1)$ & $1(2)$ & 0 & $11(1)$ & 0.829 & 0.339 & 0.47 \\
\hline \multicolumn{8}{|l|}{ Bacterial co-infections } \\
\hline S. aureus & $21(20)$ & $11(25)$ & $10(16)$ & $333(25)$ & 0.291 & 0.911 & 0.111 \\
\hline S. pneumoniae & $74(71)$ & $29(66)$ & $48(76)$ & $919(68)$ & 0.571 & 0.662 & 0.202 \\
\hline M. catarrhalis & $71(68)$ & $26(59)$ & $47(75)$ & $850(63)$ & 0.314 & 0.500 & 0.071 \\
\hline B. pertussis & $2(2)$ & 0 & $2(3)$ & $19(1)$ & 0.678 & 0.417 & 0.233 \\
\hline H. influenzae & $52(50)$ & $18(41)$ & 37 (59) & $669(50)$ & 0.977 & 0.226 & 0.152 \\
\hline H. influenzae type b & $5(5)$ & $1(2)$ & $4(6)$ & $38(3)$ & 0.254 & 0.757 & 0.122 \\
\hline M. pneumoniae & $1(1)$ & 0 & $1(2)$ & $7(1)$ & 0.561 & 0.615 & 0.258 \\
\hline C. pneumoniae & 0 & 0 & 0 & $16(1)$ & 0.263 & 0.480 & 0.395 \\
\hline HDP in nasopharynx $\mathrm{p}$ & $15(14)$ & $3(7)$ & $13(21)$ & $144(11)$ & 0.245 & 0.436 & 0.006 \\
\hline HDP in blood $\mathrm{q}$ & $4(4)$ & $3(7)$ & $1(2)$ & $67(5)$ & 0.603 & 0.529 & 0.222 \\
\hline \multicolumn{8}{|c|}{$\begin{array}{l}\text { Respiratory viral co-infections in } \\
\text { the Nasopharynx }\end{array}$} \\
\hline RSV & $24(23)$ & $7(16)$ & $18(29)$ & $320(24)$ & 0.76 & 0.234 & 0.478 \\
\hline $\mathrm{AdV}$ & $14(13)$ & $6(14)$ & $9(14)$ & $130(10)$ & 0.165 & 0.375 & 0.172 \\
\hline HMPV & $3(3)$ & $2(5)$ & $2(3)$ & $94(7)$ & 0.117 & 0.529 & 0.249 \\
\hline HBoV & $19(18)$ & $8(18)$ & 12 (19) & $152(11)$ & 0.024 & 0.166 & 0.045 \\
\hline InFV A-C & $4(4)$ & $2(5)$ & $2(3)$ & $59(5)$ & 0.618 & 0.861 & 0.546 \\
\hline PIV & $2(2)$ & $1(2)$ & $1(2)$ & 138 (10) & 0.014 & 0.117 & 0.05 \\
\hline RV & 20 (19) & $6(14)$ & $15(24)$ & 303 (23) & 0.460 & 0.167 & 0.770 \\
\hline
\end{tabular}

Abbreviations: SD: standard deviation; CRP: C-reactive protein; MCPP: microbiologically confirmed pneumococcal pneumonia; S. aureus: Staphylococcus aureus; S. pneu: Streptococcus pneumoniae; H. influenzae: Haemophilus influenzae, H. influenzae type, M. catarrhalis: Moraxella catarrahalis. B. pertussis: Bordetella pertussis; M. pneumoniae: Mycoplasma pneumoniae; C. pneumoniae: Chlamydia pneumonia; RSV: respiratory syncytial virus, HMPV: human metapneumovirus; AdV: adenovirus; PIV: parainfluenza type 1-4; HBoV: human bocavirus; HCoV: human coronavirus (OC43, NL63, 229E and HKU1); RV: rhinovirus; and InFV: influenza virus (A, B and C). a-HCoV includes cases positive for any of the four endemic species (NL63, OC43, HKU1 and/or 229E). b-AlphaCoV includes cases positive for NL63 and/or 229E. $\mathrm{c}-$ BetaCoV includes cases positive for OC43 and/or HKU1. $\mathrm{d}-p$-values from regression models comparing HCoV positive compared to $\mathrm{HCoV}$ negative cases adjusted for age in months, site of enrollment and for confounding covariates where applicable where applicable. $\mathrm{e}-p$-values from regression models comparing AlphaHCoV species (NL63 and 229E) positive compared to HCoV negative cases adjusted for age in months, site of enrolment and for confounding covariates where applicable. $\mathrm{f}-p$-values from regression models comparing BetaHCoV species (OC43 and HKU1) positive compared to HCoV negative cases adjusted for age in months, site of enrolment and for confounding covariates where applicable. g-Abnormal Chest X-ray defined as radiographically confirmed end point pneumonia consolidation or any infiltrates. $\mathrm{h}-\mathrm{A}$ child was considered to be hypoxic if (1) a room air pulse-oximetry reading indicated oxygen saturation $<90 \%$, or (2) a room air oxygen saturation was not available and child was placed on supplemental oxygen. i-Tachycardia defined as heart rate $>160$ beats per minute $(\mathrm{bpm})$ if aged $<11$ months, heart rate $>150 \mathrm{bpm}$ if aged 12-35 months, heart rate $>140 \mathrm{bpm}$ if aged 36-59 months. j-Tachypnea defined as respiratory rate $>60$ breaths / minute if aged $<2$ months, respiratory rate $>50$ breaths $/$ minute if aged 2-12 months, respiration rate $\geq 40$ breaths/minute if aged $>12$ month. $\mathrm{k}-$ Fever defined as temperature $\geq 38{ }^{\circ} \mathrm{C}$. $1-$ Leukocytosis defined as white blood cell count $>15,000$ cells $/ \mathrm{uL}$ if age $<12$ months or $>13,000$ cells $/ \mathrm{uL}$ if age $>12 \mathrm{month}$. $\mathrm{m}-\mathrm{CRP}$ defined as levels $\geq 40 \mathrm{mg} / \mathrm{L}$ were considered to potentially indicate bacterial infection. $\mathrm{n}$-Blood culture positive for any non-contaminating bacteria. o-MCPP defined as S. pneumoniae cultured from a normally sterile body fluid, including blood, pleural fluid or lung aspirate, or as pleural fluid or lung aspirate positive on PCR LytA testing. p-HDP defined as S. pneumoniae density in nasopharynx $>6.9$ log 10 copies/mL. $\mathrm{q}-\mathrm{HDP}$ defined as S.pneumoniae density in whole blood $>2.2 \log _{10}$ copies $/ \mathrm{mL}$. 
There was however no difference in the prevalence of common bacteria in the NP/OP of $\mathrm{HCoV}+$ cases compared to $\mathrm{HCoV}$ - cases. Compared to $\mathrm{HCoV}$ - cases, the $\mathrm{HCoV}+$ cases were more likely to be co-infected with $\mathrm{HBoV}$ but less likely to be co-infected with Parainfluenza viruses (Table 3).

There were no differences in the distribution of HCoV species by HIV status or clinical presentation of pneumonia. Similarly, among the controls, there were no differences in the distribution of HCoV by HIV status or presence of RTI symptoms (Figure 3). Further, $\mathrm{HCoV}$ detection was not associated with the presence of RTI symptoms or co-infections with other viral pathogens (Table S7 in Supplementary Material).

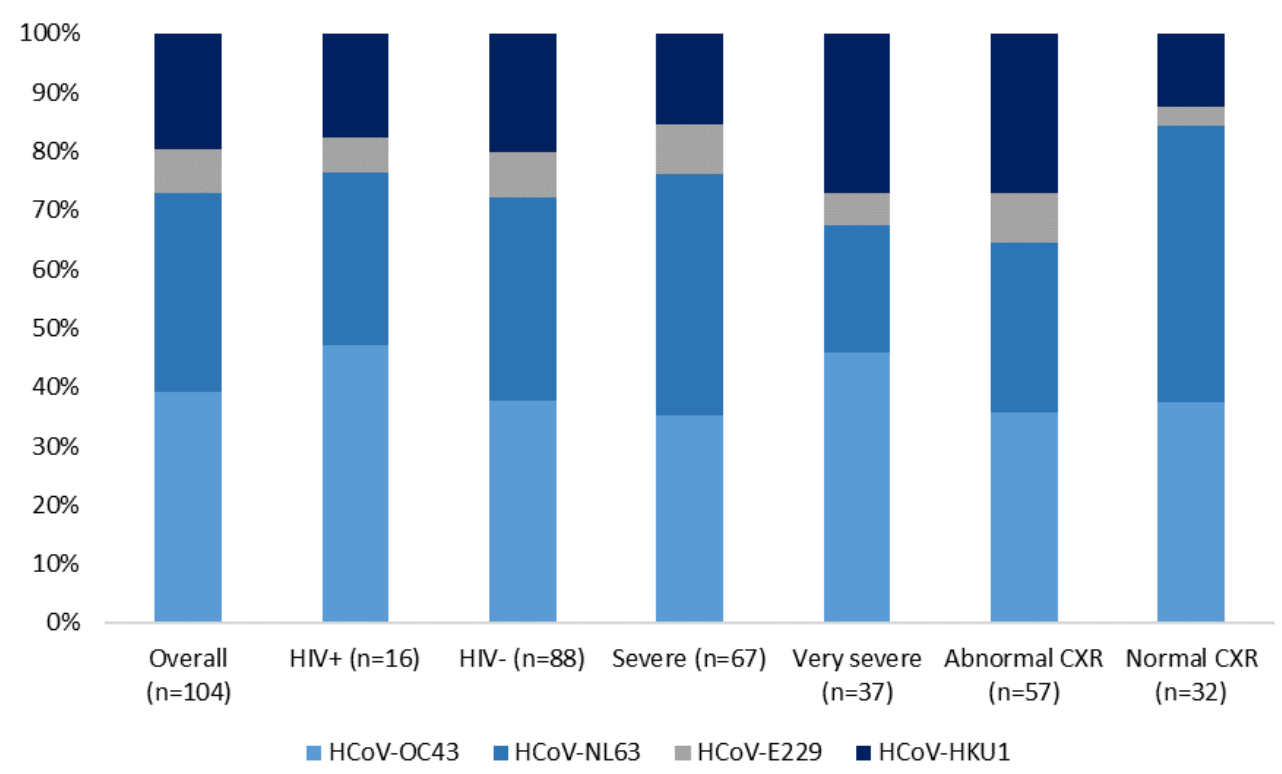

(A)

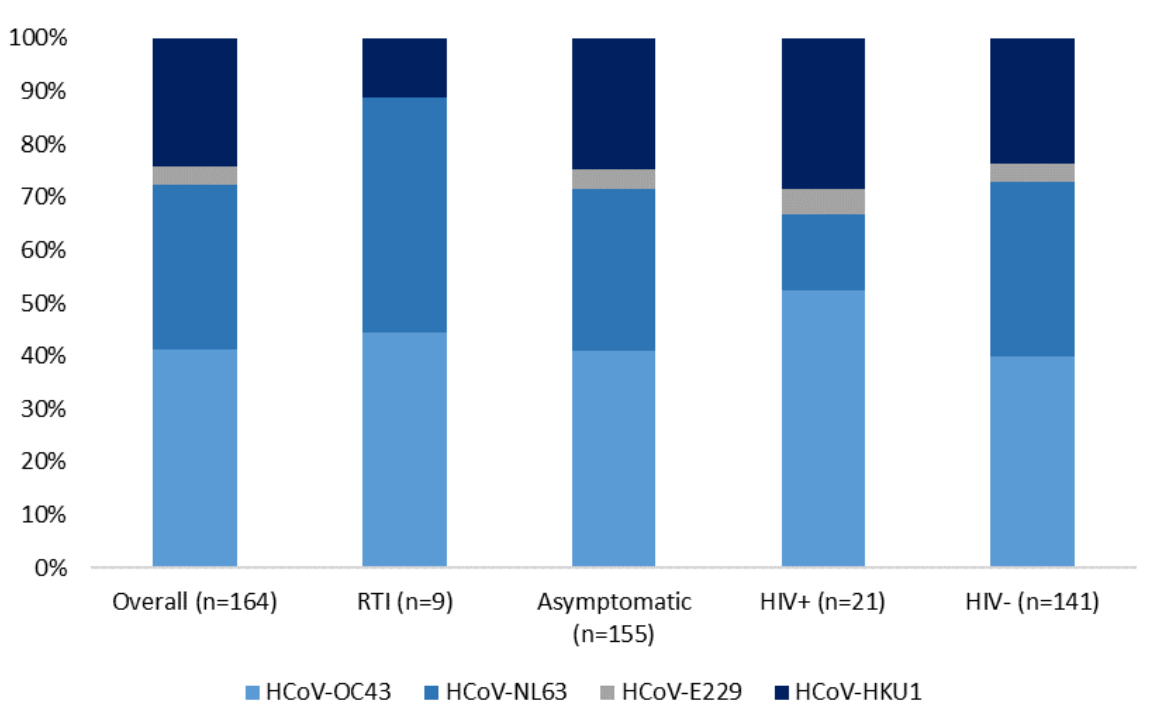

(B)

Figure 3. Distribution of $\mathrm{HCoV}$ species among $\mathrm{HCoV}$ positive cases (Panel (A)) and controls (Panel (B)).

\section{Discussion}

In this multi-country, case-control pneumonia etiology study reporting on the epidemiology of the four endemic $\mathrm{HCoV}$ infections in children under the age of 5 years, 
we found that $\mathrm{HCoV}$ detection was more prevalent in children living in the community compared to children hospitalized with pneumonia. Interestingly, this association was only evident in the asymptomatic children compared to hospitalized children. Among the children with RTI, the prevalence of $\mathrm{HCoV}$ detection was similar to that of the hospitalized children; albeit the numbers in this group were small. This association with asymptomatic controls was, however, only observed among children $>6$ months and was mainly driven by the Betacoronavirus endemic species (HCoV-OC43 and-HKU1). The prevalence of $\mathrm{HCoV}$ detection reported in this study among the cases $(7 \%)$ was similar to those reported in previous studies including in Africa [2-4,11-14]. Further, the prevalence of Alphacoronaviruses reported in this study is similar to other studies conducted in South Africa reporting on CoV-NL63 detection in sick children $[12,15,16]$. The prevalence of HCoV detection reported in this study in asymptomatic children is substantially higher than reported in another South African study [16] (11\% versus 0\%); however, in the other South African study the sample size of healthy children was very limited $(n=46)$ compared to our study $(n>1500)$.

Among controls, the prevalence of $\mathrm{HCoV}$ detection was not associated with signs and symptoms of mild respiratory tract infections, nor was it associated with HIV status. Similarly, among cases, $\mathrm{HCoV}$ detection was not associated with very severe pneumonia, signs and symptoms of more severe disease, or HIV status. However, Betacoronavirus detection among cases showed a trend to be associated with more severe pneumonia as well as longer hospital stays. $\mathrm{HCoV}$, and in particular Betacoronavirus, detection, was also associated with blood culture positivity, medically significant CRP levels and high pneumococcal densities in the NP/OP samples, all indicators of bacterial co-infection. This concurs with reports which have suggested that bacterial infections play an essential part in the pathogenesis of some viral infections progressing to severe respiratory disease [17,18]. Further, the $\mathrm{HCoV}$ positive cases, in particular Betacoronaviruses, were positively associated with Human bocavirus detection compared to the $\mathrm{HCoV}$ negative cases potentially resulting in a more severe infection [19].

Further, similar to previous studies [12,14-16,20], mixed infections with other respiratory viruses was common among the cases, whereas the asymptomatic controls were more likely to only have $\mathrm{HCoV}$ detected; thus, the mixed viral infections could have predisposed the children to more severe disease or the detection of $\mathrm{HCoV}$ in the cases was incidental to the severe disease outcome. Several studies have found that higher viral loads are associated with more severe disease [21-24] but in this study there were no differences in the viral loads between the $\mathrm{HCoV}$ positive cases and asymptomatic controls thus potentially further indicating that the $\mathrm{HCoV}$ detection in cases was incidental to the severe disease outcome. From SARS-CoV-2 studies we also know that $\mathrm{HCoV}$ can shed for up to 3 weeks [25] after infection took place thus detection might not be indicative of a current infection and our study used URT sampling as a proxy for sampling the site of infection. Direct sampling of the LRT, including lung aspirates and bronchoalveolar lavage, would provide more direct evidence on the causal pathogen of the pneumonia episode.

Several studies have looked at the seasonality of $\mathrm{HCoV}[11,15,16,26-29]$. However, the majority of these are in high income countries in the Northern Hemisphere which have very defined seasons. To our knowledge, this is the first study reporting on the seasonality of $\mathrm{HCoV}$ in both hospitalized children and asymptomatic controls in the Southern Hemisphere where the seasons are more temperate. In both Zambia and South Africa, $\mathrm{HCoV}$ was detected throughout the year. However, in Zambia the peak of infections tended to occur during the colder months (June to September); which was mainly driven by the Betacoronaviruses. Whether such transmission peaks apply to the current circulation of SARS-CoV-2, part of the Betacoronavirus genera, in Southern Hemisphere countries has yet to be determined.

Even though Zambia and South Africa have high HIV rates in the general population ( $12.5 \%$ and $20 \%$, respectively) [6]; mother to child transmission prevention strategies have likely reduced HIV rates in children [30] $(<14 \%$ in our population). Thus, we lacked statistical power to study the clinical epidemiology of $\mathrm{HCoV}$ in HIV positive children 
living in South Africa and Zambia. However, it did appear that HIV was not a risk factor for more severe $\mathrm{HCoV}$ disease with HIV positive asymptomatic controls having a higher prevalence of $\mathrm{HCoV}$ detection than the HIV positive cases. Only one other case-control study looked at $\mathrm{HCoV}$ detection in a high HIV population [16]; however, due to the even more limited control enrolment they too failed to study the risk factor of HIV and HCoV. Other limitation included the cross-sectional design which limited our ability to study the temporal association of $\mathrm{HCoV}$ and timing of disease onset and controls were not followed up after enrolment into the study to determine if they went on to develop disease. Additionally, our study used upper respiratory tract sampling as a proxy for actual site of infection, namely, the lower respiratory tract. Direct sampling would provide better evidence for the actual causal agent of the pneumonia episode; these samples are however invasive and difficult to perform.

\section{Conclusions}

In conclusion, $\mathrm{HCoV}$ and in particular endemic Betacoronaviruses were more commonly detected in asymptomatic children, compared to children requiring hospitalization with severe pneumonia. Further, there was little evidence that $\mathrm{HCoVs}$ were directly contributing to the severe disease outcome observed in this study. However, co-infections with other common respiratory viruses, namely human bocavirus, and bacteria cannot be dismissed when it comes to childhood disease with more studies required to fully elucidate the etiologic contribution of $\mathrm{HCoV}$.

Supplementary Materials: The following are available online at https:/ /www.mdpi.com/article/10 $.3390 / \mathrm{v} 13081513 / \mathrm{s} 1$, Table S1: Number of study subjects enrolled and tested for HCoV—percent positive by site of enrolment, Table S2: Number of study subjects enrolled and tested for the four endemic $\mathrm{HCoV}$ species, Table S3: Number of study subjects enrolled and tested for $\mathrm{HCoV}$-percent positive by age and HIV-1 infection status, Table S4: Characteristics of $\mathrm{HCoV}+$ in HIV+ cases ( $\mathrm{N}=16)$ and controls $(\mathrm{N}=21)$, Table S5: Characteristics of $\mathrm{HCoV}+$ in HIV- cases $(\mathrm{N}=88)$ and controls $(N=141)$, Table S6: Demographic, clinical characteristics and markers of bacterial and respiratory viral co-infections among severe and very-severe pneumonia cases identified with Human coronavirus infection, Table S7: Demographic, clinical characteristics and markers of bacterial and respiratory viral co-infections among community controls identified with Human coronavirus infection.

Author Contributions: Conceptualization, V.L.B., D.E.P. and S.A.M.; methodology, V.L.B., S.A.M.; validation, V.L.B., D.P.M., A.M., D.M.T.; formal analysis, V.L.B., D.E.P.; investigation, V.L.B., S.A.M., D.P.M.; data curation, V.L.B., A.M., D.M.T., G.K., L.M.; writing-V.L.B.; writing-D.P.M., A.M., D.E.P., D.M.T., G.K., L.M., S.A.M.; supervision, S.A.M.; project administration, V.L.B., S.A.M., D.P.M.; funding acquisition, S.A.M. and D.M.T. All authors have read and agreed to the published version of the manuscript.

Funding: This work was supported by The Bill \& Melinda Gates Foundation grant to the International Vaccine Access Center, Department of International Health, Johns Hopkins Bloomberg School of Public Health (grant number 48968).

Institutional Review Board Statement: The PERCH study was reviewed by 10 different institution review boards (IRB) - the initial overall clinical and laboratory testing protocols were reviewed by the JHSPH's IRB after which the protocols were customized for each of the sites and reviewed by their local boards. The revised protocols and approvals for each site were then submitted to the JHSPH's IRB as amendments. This allowed for the collective ownership of the project by the PERCH executive committee as well across the sites. The ethical approvals for each of the sites are listed below:

1. Study Site: South Africa conducted by the Respiratory and Meningeal Pathogens Research Unit, Wits Health Consortium, based at Chris Hani Baragwanath Academic Hospital

Wits HREC Approval number: M10M101129Principal investigator: Prof Shabir A. Madhi

2. Study Site: Lusaka, Zambia at the Boston University Institution

Approval number from the Blue Panel IRB: HP-29860Approval from the ERES Converge IRB: 2010-Dec-001Principal Investigator: Dr Donald Thea 
Informed Consent Statement: Informed consent was obtained from all subjects involved in the study.

Data Availability Statement: All data is available at https:/ / clinepidb.org/ce/app (accessed on 12 May 2021).

Acknowledgments: We acknowledge the work of all PERCH Contributors who were involved in data collection at the local sites and central laboratories, members of the PERCH Chest Radiograph Reading Panel, and Shalika Jayawardena and Rose Watt from Canterbury Health Laboratories. Finally, we offer sincere thanks to the patients and families who participated in the study.

Conflicts of Interest: S.A.M. has received honoraria for advisory board participation from Bill \& Melinda Gates Foundation, Pfizer, Medimmune, and Novartis and institutional grants from GSK, Novartis, Pfizer, Minervax, and Bill \& Melinda Gates Foundation and has served on speakers bureau for Sanofi Pasteur and GSK. M.D.K. has received funding for consultancies from Merck, Pfizer, Novartis, and grant funding from Merck. C.P. has received grant funding from Merck. K.L.O. has received grant funding from GlaxoSmithKline and Pfizer and participates on technical advisory boards for Merck, Sanofi-Pasteur, PATH, Affinivax, and ClearPath. K.L.K. has received grant funding from Merck Sharp \& Dohme. W.A.B. reported funding from Sanofi, PATH, Bill \& Melinda Gates Foundation (BMGF), and contributions to contemporaneous studies from Serum Institute of India, LTD, Roche and Sanofi. All other authors: No reported conflicts. Conflicts that the editors consider relevant to the content of the manuscript have been disclosed.

\section{References}

1. Fehr, A.R.; Perlman, S. Coronaviruses: An overview of their replication and pathogenesis. In Coronaviruses; Springer: Berlin, Germany, 2015; pp. 1-23.

2. Cabeça, T.K.; Granato, C.; Bellei, N. Epidemiological and clinical features of human coronavirus infections among different subsets of patients. Influenza Other Respir. Viruses 2013, 7, 1040-1047. [CrossRef]

3. Zimmermann, P.; Curtis, N. Coronavirus Infections in Children Including COVID-19. Pediatr Infect. Dis J. 2020, 39, 355-368. [CrossRef]

4. Kuypers, J.; Martin, E.T.; Heugel, J.; Wright, N.; Morrow, R.; Englund, J.A. Clinical disease in children associated with newly described coronavirus subtypes. Pediatrics 2007, 119, e70-e76. [CrossRef]

5. Baillie, V.L.; Moore, D.P.; Mathunjwa, A.; Morailane, P.; Simões, E.A.; Madhi, S.A. Molecular subtyping of human rhinovirus in children from three sub-Saharan African countries. J. Clin. Microbiol. 2019, 57, e00723-19. [CrossRef]

6. Levine, O.S.; O’Brien, K.L.; Deloria-Knoll, M.; Murdoch, D.R.; Feikin, D.R.; DeLuca, A.N.; Driscoll, A.J.; Baggett, H.C.; Brooks, W.A.; Howie, S.R. The Pneumonia Etiology Research for Child Health Project: A 21st century childhood pneumonia etiology study. Clin. Infect. Dis. 2012, 54, S93-S101. [CrossRef]

7. Deloria-Knoll, M.; Feikin, D.R.; Scott, J.A.G.; O’Brien, K.L.; DeLuca, A.N.; Driscoll, A.J.; Levine, O.S.; Group, P.M.W. Identification and selection of cases and controls in the Pneumonia Etiology Research for Child Health project. Clin. Infect. Dis. 2012, 54, S117-S123. [CrossRef]

8. Murdoch, D.; O’Brien, K.; Driscoll, A.; Karron, R.; Bhat, N. Laboratory methods for determining pneumonia etiology in children. Clin. Infect. Dis. 2012, 54, S146-S152. [CrossRef]

9. $\quad$ Baggett, H.C.; Watson, N.L.; Deloria Knoll, M.; Brooks, W.A.; Feikin, D.R.; Hammitt, L.L.; Howie, S.R.; Kotloff, K.L.; Levine, O.S.; Madhi, S.A. Density of upper respiratory colonization with Streptococcus pneumoniae and its role in the diagnosis of pneumococcal pneumonia among children aged $<5$ years in the PERCH study. Clin. Infect. Dis. 2017, 64, S317-S327.

10. Morpeth, S.C.; Deloria Knoll, M.; Scott, J.A.G.; Park, D.E.; Watson, N.L.; Baggett, H.C.; Brooks, W.A.; Feikin, D.R.; Hammitt, L.L.; Howie, S.R. Detection of pneumococcal DNA in blood by polymerase chain reaction for diagnosing pneumococcal pneumonia in young children from low-and middle-income countries. Clin. Infect. Dis. 2017, 64, S347-S356. [CrossRef]

11. Prill, M.M.; Iwane, M.K.; Edwards, K.M.; Williams, J.V.; Weinberg, G.A.; Staat, M.A.; Willby, M.J.; Talbot, H.K.; Hall, C.B.; Szilagyi, P.G. Human coronavirus in young children hospitalized for acute respiratory illness and asymptomatic controls. Pediatric Infect. Dis. J. 2012, 31, 235-240. [CrossRef]

12. Smuts, H.; Workman, L.; Zar, H.J. Role of human metapneumovirus, human coronavirus NL63 and human bocavirus in infants and young children with acute wheezing. J. Med. Virol. 2008, 80, 906-912. [CrossRef]

13. Taylor, S.; Lopez, P.; Weckx, L.; Borja-Tabora, C.; Ulloa-Gutierrez, R.; Lazcano-Ponce, E.; Kerdpanich, A.; Weber, M.A.R.; de Los Santos, A.M.; Tinoco, J.-C. Respiratory viruses and influenza-like illness: Epidemiology and outcomes in children aged 6 months to 10 years in a multi-country population sample. J. Infect. 2017, 74, 29-41. [CrossRef]

14. Munywoki, P.K.; Koech, D.C.; Agoti, C.N.; Cane, P.A.; Medley, G.F.; Nokes, D.J. Continuous invasion by respiratory viruses observed in rural households during a respiratory syncytial virus seasonal outbreak in coastal Kenya. Clin. Infect. Dis. 2018, 67, 1559-1567. [CrossRef]

15. Smuts, H. Human coronavirus NL63 infections in infants hospitalised with acute respiratory tract infections in South Africa. Influenza Other Respir. Viruses 2008, 2, 135-138. [CrossRef] 
16. Venter, M.; Lassaunière, R.; Kresfelder, T.L.; Westerberg, Y.; Visser, A. Contribution of common and recently described respiratory viruses to annual hospitalizations in children in South Africa. J. Med. Virol. 2011, 83, 1458-1468. [CrossRef]

17. Madhi, S.A.; Ludewick, H.; Kuwanda, L.; Van Niekerk, N.; Cutland, C.L.; Little, T.; Klugman, K.P. Pneumococcal coinfection with human Metapneumovirus. J. Infect. Dis. 2006, 193, 1236-1943. [CrossRef]

18. O'Callaghan-Gordo, C.; Bassat, Q.; Morais, L.; Díez-Padrisa, N.; Machevo, S.; Nhampossa, T.; Nhalungo, D.; Sanz, S.; Quintó, L.; Alonso, P.L. Etiology and epidemiology of viral pneumonia among hospitalized children in rural Mozambique: A malaria endemic area with high prevalence of human immunodeficiency virus. Pediatric Infect. Dis. J. 2011, 30, 39-44. [CrossRef]

19. Calvo, C.; Alcolea, S.; Casas, I.; Pozo, F.; Iglesias, M.; Gonzalez-Esguevillas, M.; García-García, M.L. A 14-year prospective study of human coronavirus infections in hospitalized children: Comparison with other respiratory viruses. Pediatric Infect. Dis. J. 2020, 39, 653-657. [CrossRef]

20. Pretorius, M.A.; Tempia, S.; Walaza, S.; Cohen, A.L.; Moyes, J.; Variava, E.; Dawood, H.; Seleka, M.; Hellferscee, O.; Treurnicht, F.; et al. The role of influenza, RSV and other common respiratory viruses in severe acute respiratory infections and influenza-like illness in a population with a high HIV sero-prevalence, South Africa 2012-2015. J. Clin. Virol. 2016, 75, 21-26. [CrossRef]

21. Esposito, S.; Daleno, C.; Scala, A.; Castellazzi, L.; Terranova, L.; Papa, S.S.; Longo, M.; Pelucchi, C.; Principi, N. Impact of rhinovirus nasopharyngeal viral load and viremia on severity of respiratory infections in children. Eur. J. Clin. Microbiol. Infect. Dis. 2014, 33, 41-48. [CrossRef]

22. Bruning, A.H.; Thomas, X.V.; van der Linden, L.; Wildenbeest, J.G.; Minnaar, R.P.; Jansen, R.R.; de Jong, M.D.; Sterk, P.J.; van der Schee, M.P.; Wolthers, K.C. Clinical, virological and epidemiological characteristics of rhinovirus infections in early childhood: A comparison between non-hospitalised and hospitalised children. J. Clin. Virol. 2015, 73, 120-126. [CrossRef]

23. Takeyama, A.; Hashimoto, K.; Sato, M.; Sato, T.; Kanno, S.; Takano, K.; Ito, M.; Katayose, M.; Nishimura, H.; Kawasaki, Y. Rhinovirus load and disease severity in children with lower respiratory tract infections. J. Med. Virol. 2012, 84, 1135-1142. [CrossRef]

24. Ambrosioni, J.; Bridevaux, P.-O.; Aubert, J.-D.; Soccal, P.; Wagner, G.; Kaiser, L. Role of rhinovirus load in the upper respiratory tract and severity of symptoms in lung transplant recipients. J. Clin. Virol. 2015, 64, 1-5. [CrossRef]

25. Lu, Y.; Li, Y.; Deng, W.; Liu, M.; He, Y.; Huang, L.; Lv, M.; Li, J.; Du, H. Symptomatic infection is associated with prolonged duration of viral shedding in mild coronavirus disease 2019: A retrospective study of 110 children in Wuhan. Pediatric Infect. Dis. J. 2020, 39, e95-e99. [CrossRef]

26. Heimdal, I.; Moe, N.; Krokstad, S.; Christensen, A.; Skanke, L.H.; Nordbø, S.A.; Døllner, H. Human Coronavirus in Hospitalized Children With Respiratory Tract Infections: A 9-Year Population-Based Study From Norway. J. Infect. Dis. 2019, 219, 1198-1206. [CrossRef]

27. Monto, A.S.; DeJonge, P.M.; Callear, A.P.; Bazzi, L.A.; Capriola, S.B.; Malosh, R.E.; Martin, E.T.; Petrie, J.G. Coronavirus Occurrence and Transmission Over 8 Years in the HIVE Cohort of Households in Michigan. J. Infect. Dis. 2020, 222, 9-16. [CrossRef] [PubMed]

28. Fairchok, M.P.; Martin, E.T.; Chambers, S.; Kuypers, J.; Behrens, M.; Braun, L.E.; Englund, J.A. Epidemiology of viral respiratory tract infections in a prospective cohort of infants and toddlers attending daycare. J. Clin. Virol. 2010, 49, 16-20. [CrossRef]

29. Ofner-Agostini, M.; Wallington, T.; Henry, B.; Low, D.; McDonald, L.; Berger, L.; Mederski, B. Investigation of the second wave (phase 2) of severe acute respiratory syndrome (SARS) in Toronto, Canada. What happened? Can. Commun. Dis. Rep. 2008, 34, $1-11$.

30. Siegfried, N.; van der Merwe, L.; Brocklehurst, P.; Sint, T.T. Antiretrovirals for reducing the risk of mother-to-child transmission of HIV infection. Cochrane Database Syst. Rev. 2011. [CrossRef] 